\title{
Optimization of Sodium Bicarbonate Production Using Response Surface Methodology (RSM)
}

\author{
Zaid Adnan Abdel-Rahman ${ }^{1}$, Hussein Habib Hamed ${ }^{2}$, Farah Kahtan Khalaf ${ }^{3}$ \\ ${ }^{1},{ }^{3}$ Department of Chemical Engineering, College of Engineering, Tikrit University \\ ${ }^{2}$ Department of Fuel \& Energy, Technical College Kirkuk, Iraq. \\ zaid572010@yahoo.com
}

\begin{abstract}
The main objective of this study was to evaluate the use of batch bubble column to produce high particle size (>300 micron) of sodium bicarbonate product to improve filtration and drying operations in the production process. Lab scale batch bubble column of $80 \mathrm{~mm}$ diameter and $0.5 \mathrm{~m}$ height was used to study the process for sodium bicarbonate production using $20 \%$ sodium carbonate solution as a starting solution. Three operating variables were considered, $\mathrm{CO}_{2}$ gas content $(20-100 \%)$, temperature $\left(30-70{ }^{\circ} \mathrm{C}\right)$ and time $(0.5-2.5 \mathrm{~h})$. The bicarbonate yield and crystals size were considered to be the objective variables of the process. Response surface methodology (RSM) was used with central composite design (CCD) of experiments. Empirical polynomial multivariable equations were obtained. The reaction time was found to be the most effective operating condition on the yield of sodium bicarbonate, and temperature was found to be the most effective operating condition on crystal size of sodium bicarbonate. The optimum conditions achieved 400 microns particle size at temperature $70{ }^{\circ} \mathrm{C}$ and time 2.5 h. Kinetics study of the process showed that zero order reaction with both sodium carbonate and $\mathrm{CO}_{2}$ concentrations was approximately fitted the experimental data, useful for shortcut process design purposes.
\end{abstract}

Keywords: Sodium bicarbonate production, batch bubble column, RSM, optimization.

Paper History: Received: (20/10/2016), Accepted: (15/3/2017)

\section{Introduction}

Sodium bicarbonate (baking soda) has many applications; animal feeds, paper industry, plastic foaming, water treatment, leather treatment, flue gas treatment, detergent and cleaning products, drilling mud to improve fluidity, fire extinguisher powder, human food products and domestic uses, and pharmaceutical applications.
Sodium bicarbonate $\left(\mathrm{NaHCO}_{3}\right)$ appears as an intermediate product in soda ash (sodium carbonate) production, Solvay process. However it is produced from purified sodium carbonate rather than from purifying the intermediate, because of several reasons: the difficulty in drying the intermediate bicarbonate; the presence of a small amount of ammonia lead to be unfit for many uses; and containing many impurities in addition to ammonia [1].

The production process of purified sodium bicarbonate is by the dispersion of a $\mathrm{CO}_{2}$ gas in a solution of purified soda ash $\left(\mathrm{Na}_{2} \mathrm{CO}_{3}\right)$ with the following reaction equations [2];

$$
\begin{aligned}
& \mathrm{CO}_{2}(\mathrm{~g}) \longleftrightarrow \mathrm{CO}_{2}(\mathrm{l}) \\
& \mathrm{CO}_{2}(\mathrm{l})+\mathrm{OH}^{-} \longleftrightarrow \mathrm{HCO}_{3}^{-} \\
& \mathrm{HCO}_{3}^{-}+\mathrm{OH}^{-} \longleftrightarrow \mathrm{CO}_{3}^{-2} \\
& \mathrm{Na}^{+}+\mathrm{HCO}_{3}^{-} \longleftrightarrow \mathrm{NaHCO}_{3}
\end{aligned}
$$

With the following overall reaction;

$\mathrm{Na}_{2} \mathrm{CO}_{3}+\mathrm{CO}_{2}+\mathrm{H}_{2} \mathrm{O} \longleftrightarrow 2 \mathrm{NaHCO}_{3}$

A super-saturation solution of $\mathrm{NaHCO}_{3}$ in the liquid is formed and precipitation of solid $\mathrm{NaHCO}_{3}$ occurs. The equilibrium between $\mathrm{NaHCO}_{3}, \mathrm{Na}_{2} \mathrm{CO}_{3}$ and $\mathrm{CO}_{2}$ depends on temperature, concentrations of carbonate and bicarbonate, and $\mathrm{CO}_{2}$ partial pressure over the solution. The process of production of the bicarbonate has a large number of complex physical and chemical phenomena; gas-liquid mass transfer, reaction, solid crystallization in two-component (sodium carbonate and sodium bicarbonate) solution in equilibrium, and three phase gas-liquid-solid hydrodynamics. Sodium bicarbonate production yield and crystal size distribution (CSD) were the most important dependent variables of the process. Previous works studied the effect of operating variables on the reaction and crystallization kinetics. The recommended reactor types for the production of sodium bicarbonate were bubble column [4, $5,6,7 \& 8]$ and mechanical stirred tank $[9,10]$. Bubble column is the commonly used unit 
operations equipment for sodium bicarbonate production.

Broul et al [11] proposed an equation, Equation 6 , of the solubility of $\mathrm{NaHCO}_{3}$ in the presence of $\mathrm{Na}_{2} \mathrm{CO}_{3}$ at super-saturation, which compared with pure sodium bicarbonate solubility data given by Miller [12] as shown in Figure 1.

$$
\begin{gathered}
\log x^{*}=6.71535-\frac{843.0681}{T}- \\
2.24336 \log T
\end{gathered}
$$

Where;

$\mathrm{x}^{*}$ : Mole fraction of sodium bicarbonate at super-saturation.

$\mathrm{T}$ : Liquid temperature $(\mathrm{K})$.

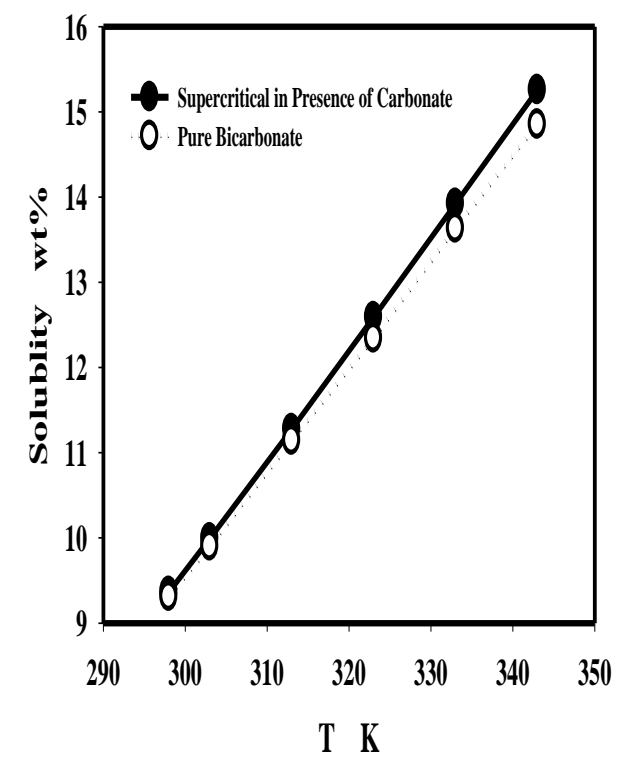

Figure 1: Comparison of solubility of pure bicarbonate [12] with super-saturation in presence of carbonate [11]

All previous works investigated continuous process mode. Little work on batch bubble column reactor has been found in the literature to produce sodium bicarbonate.

The objectives of the present study are to evaluate the use of batch bubble column to produce high particle size (>300 micron) of sodium bicarbonate product to improve filtration and drying operations in the production process, to design and to perform experiments for the effect of the operating conditions (temperature, time, and $\mathrm{CO}_{2}$ gas content) on the bicarbonate yield \& particle size using response surface methodology (RSM), to obtain the optimum conditions of the process, and to study the kinetics of the reaction.

\section{Experimental Work}

Commercial light soda ash 99.5 purity, supplied by ŞişECAM Company Turkey, was used.
Distilled water, from Koprulu Trade Company Kirkuk-Iraq, was used to prepare saturated solution of sodium carbonate. Carbon dioxide $\left(\mathrm{CO}_{2}\right)$ cylinder $(99.9 \%)$ supplied by Mustafa Otrakici bureau, Kirkuk-Iraq.

Figure 2 shows the methodology diagram for the production of sodium bicarbonate (NaHCO3) process, includes four stages; bubble column process, filtration, drying, and sieve analysis for crystal size distribution (CSD). Lab-scale batch bubble column of inner diameter $\mathrm{D}=80 \mathrm{~mm}$ and height $\mathrm{H}=500 \mathrm{~mm}$ of about 2 liters volume was used. Column temperature was controlled digitally, placed in water bath. Oil free air compressor was used to supply the air to the system, using gas flow meter to regulate the air flow rate. $\mathrm{CO}_{2}$ cylinder with pressure regulator and flow meter were used to supply the $\mathrm{CO}_{2}$ to the system. Tube distributor of single nozzle of $6 \mathrm{~mm}$ diameter at a depth $50 \mathrm{~mm}$ from the bottom of column was used to disperse the gas mixture $\left(\mathrm{CO}_{2}\right.$ gas and air). Figure 3 shows the experimental set-up.

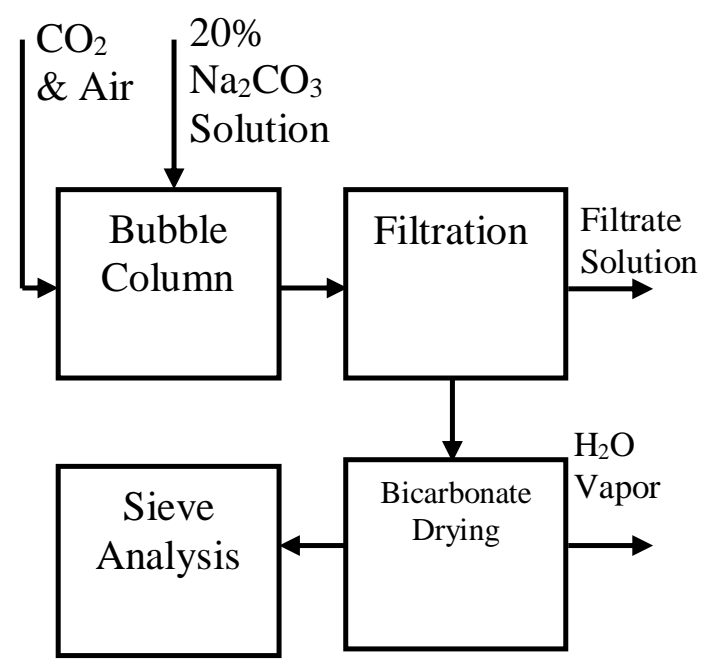

Figure 2: The methodology diagram 


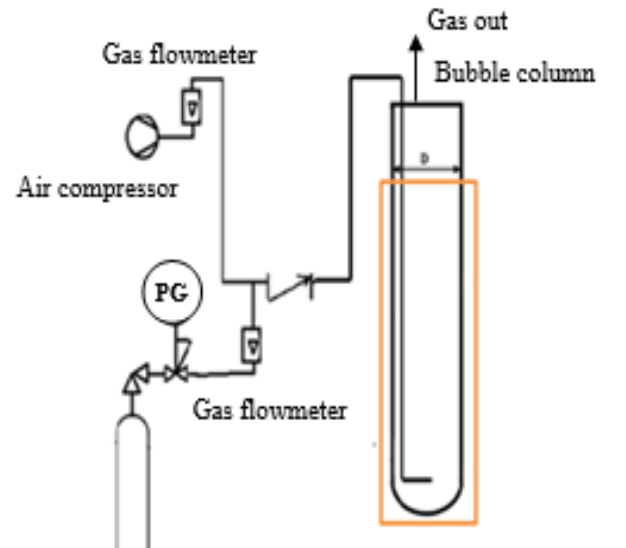

Water bath

$\mathrm{CO}_{2}$ cylinder

Figure 3: Lab-Scale batch of bubble column experimental Set-up

Three operating variables were considered in the present work; $\mathrm{CO}_{2}$ gas content $\left(\mathrm{y}_{\mathrm{CO}}=20-\right.$ $100 \%)$, temperature $\left(\mathrm{T}=30-70{ }^{\circ} \mathrm{C}\right)$, and time $(\mathrm{t}=0.5-2.5 \mathrm{~h})$. Constant gas flow rate, of 10 $1 / \mathrm{min}$ with a superficial gas velocity of $0.03 \mathrm{~m} / \mathrm{s}$, was selected to give homogeneous flow regime in the bubble column. A solution of $\mathrm{Na}_{2} \mathrm{CO}_{3}$ of $20 \%$ concentration was used as starting solution.

Gas hold-up was calculated experimentally as following:

$$
\varepsilon_{g}=\frac{\Delta L}{L}
$$

Where, $\Delta \mathrm{L}$ is the height of solution difference before and after gas mixture flow. The value of $\varepsilon_{\mathrm{g}}$ of about (12-13\%) was noticed for the constant gas flowrate used.

Running the experiment at a specified temperature and $\mathrm{CO}_{2}$ gas content until $\mathrm{NaHCO}_{3}$ crystals began formed; set it as $\mathrm{t}_{1}$ the time before crystallization. The run was continued for a specified reaction time. The total time was; $t_{2}=$ $\mathrm{t}_{1}+$ reaction time.

A Buchner funnel vacuum filtration was used to filter the cake of $\mathrm{NaHCO}_{3}$ crystals produced. Drying the $\mathrm{NaHCO}_{3}$ cake was performed in an oven at $65{ }^{\circ} \mathrm{C}$ for 8 hours. The yield of the bicarbonate solid product was calculated from simple mass balance of the overall reaction Equation 5, by the following equation;

$$
Y_{s}=\frac{m_{\text {Bicarb }}}{2 m_{\text {Carb }}} \frac{M_{\text {Carb }}}{M_{\text {Bicarb }}}
$$

The crystal size was measured using sieves analysis apparatus at different size, and the volume average particle size diameter $\left(d_{p}\right)$ was calculated by;

$$
\mathrm{d}_{\mathrm{p}}=\sum \mathrm{d}_{\mathrm{p}_{\mathrm{i}}} \mathrm{z}_{\mathrm{i}}
$$

Where $d_{p_{i}}$ is the particle size in sieve $i$ and $z_{i}$ is the weight fraction of particle size in sieve $i$.

\section{Experiments Design}

In order to study the effect of operating conditions for sodium bicarbonate production and to investigate the interaction between the process variables, Design Expert 6.0.6 software was used, using a central composite design (CCD) of experiments. Three process variables; reaction temperature $(\mathrm{T}), \mathrm{CO}_{2}$ gas content $\left(\mathrm{y}_{\mathrm{CO} 2}\right)$, and reaction time $(\mathrm{t})$, were chosen with center values of $50{ }^{\circ} \mathrm{C}, 60 \%$, and $1.5 \mathrm{~h}$ respectively, after performing some primary experiments. Coded and actual process variables used in experiments design are

\begin{tabular}{|c|c|c|c|c|c|}
\hline \multirow{2}{*}{$\begin{array}{c}\text { Process } \\
\text { variables }\end{array}$} & \multicolumn{5}{|c|}{ Coded and actual variables } \\
\hline & -2 & -1 & 0 & 1 & 2 \\
\hline $\mathrm{T} \quad{ }^{\circ} \mathrm{C}$ & 30 & 40 & 50 & 60 & 70 \\
\hline $\mathrm{y}_{\mathrm{CO} 2} \%$ & 20 & 40 & 60 & 80 & 100 \\
\hline $\mathrm{h}$ & 0.5 & 1 & 1.5 & 2 & 2.5 \\
\hline
\end{tabular}
presented in Table 1.

Table 1 Coded and actual process variables.

A second-order polynomial response surface model of a central composite design (CCD) required 20 experiments, as shown in Table 2 . The center points are usually repeated 6 times to determine the experimental error and the reproducibility of the data ${ }^{(13)}$.

Table 2 Experiments design (CCD), including results.

\begin{tabular}{|c|c|c|c|c|c|c|c|c|}
\hline $\begin{array}{c}\text { Exp. } \\
\text { No. }\end{array}$ & $\begin{array}{c}\mathrm{T} \\
{ }^{\circ} \mathrm{C}\end{array}$ & $\begin{array}{c}\text { yco2 } \\
\%\end{array}$ & $\begin{array}{c}\mathrm{t} \\
\mathrm{h}\end{array}$ & $\mathrm{X}_{1}$ & $\mathrm{X}_{2}$ & $\mathrm{X}_{3}$ & $\begin{array}{c}\text { Ys } \\
\%\end{array}$ & $\begin{array}{c}\mathrm{dp} \\
\mu \mathrm{m}\end{array}$ \\
\hline 1 & 40 & 40 & 1 & -1 & -1 & -1 & 30.7 & 238 \\
\hline 2 & 60 & 40 & 1 & +1 & -1 & -1 & 21.8 & 273 \\
\hline 3 & 40 & 80 & 1 & -1 & +1 & -1 & 42.6 & 208 \\
\hline 4 & 60 & 80 & 1 & +1 & +1 & -1 & 41.2 & 282 \\
\hline 5 & 40 & 40 & 2 & -1 & -1 & +1 & 50.7 & 234 \\
\hline 6 & 60 & 40 & 2 & +1 & -1 & +1 & 42.3 & 345 \\
\hline 7 & 40 & 80 & 2 & -1 & +1 & +1 & 63.1 & 237 \\
\hline 8 & 60 & 80 & 2 & +1 & +1 & +1 & 53.7 & 330 \\
\hline 9 & 30 & 60 & 1.5 & -2 & 0 & 0 & 50.3 & 182 \\
\hline 10 & 70 & 60 & 1.5 & +2 & 0 & 0 & 44.2 & 304 \\
\hline 11 & 50 & 20 & 1.5 & 0 & -2 & 0 & 23.9 & 271 \\
\hline 12 & 50 & 100 & 1.5 & 0 & +2 & 0 & 59.8 & 264 \\
\hline 13 & 50 & 60 & 0.5 & 0 & 0 & -2 & 18.2 & 289 \\
\hline 14 & 50 & 60 & 2.5 & 0 & 0 & +2 & 59.8 & 314 \\
\hline 15 & 50 & 60 & 1.5 & 0 & 0 & 0 & 46.8 & 271 \\
\hline 16 & 50 & 60 & 1.5 & 0 & 0 & 0 & 45.5 & 268 \\
\hline 17 & 50 & 60 & 1.5 & 0 & 0 & 0 & 47.8 & 274 \\
\hline 18 & 50 & 60 & 1.5 & 0 & 0 & 0 & 46.1 & 266 \\
\hline 19 & 50 & 60 & 1.5 & 0 & 0 & 0 & 46.6 & 277 \\
\hline
\end{tabular}

\section{Results and Discussion}

The process of sodium bicarbonate production was analyzed by the application of the response surface methodology (RSM). Design Expert 6.0.6 software was used. Two second-order polynomial models were obtained to predict the 
bicarbonate yield and particle size as a function of three operating variables; reaction temperature $\left(\mathrm{T}=30-70 \quad{ }^{\circ} \mathrm{C}\right), \quad \mathrm{CO}_{2} \quad$ mole percentage $\left(\mathrm{y}_{\mathrm{CO} 2}=20-100 \%\right)$, and time $(\mathrm{t}=0.5$ $2.5 \mathrm{~h})$.

The analysis of variances (ANOVA), neglecting the insignificant terms, resulted the two empirical equations; Equation 10 and Equation 11. Figures 4 and 5 show good correlations of the predicted verses actual (experimental) for bicarbonate yield and particle size respectively.

$\mathrm{Y}_{\mathrm{s}}=-23.23-0.252 \mathrm{~T}+0.78 \mathrm{y}_{\mathrm{CO} 2}+43.46 \mathrm{t}-$ $3.19 \times 10^{-3} \mathrm{yCO}^{2}-7.96 \mathrm{t}^{2}$

$$
\left(\mathrm{R}^{2}=0.9746, \mathrm{Std}=2.27\right)
$$

$\mathrm{d}_{\mathrm{p}}=127.73214+7.00804 \mathrm{~T}-184.80357 \mathrm{t}-$ $0.070893 \mathrm{~T}^{2}+30.14286 \mathrm{t}^{2}+2.37500 \mathrm{~T} \mathrm{t}$ $\left(\mathrm{R}^{2}=0.9413, \mathrm{Std}=10.8\right)$

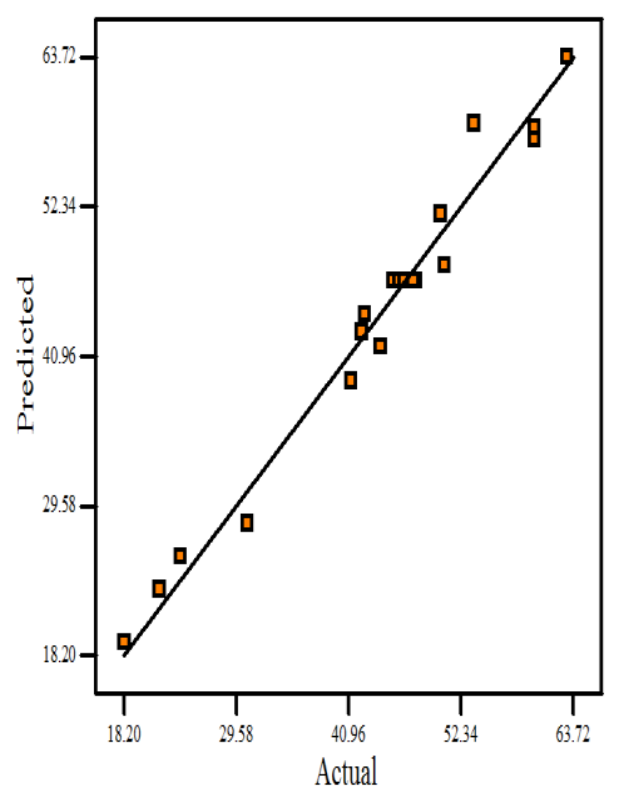

Figure 4: Predicted versus actual $\mathrm{NaHCO} 3$ yield $\left(\mathrm{Y}_{\mathrm{s}}, \%\right)$.

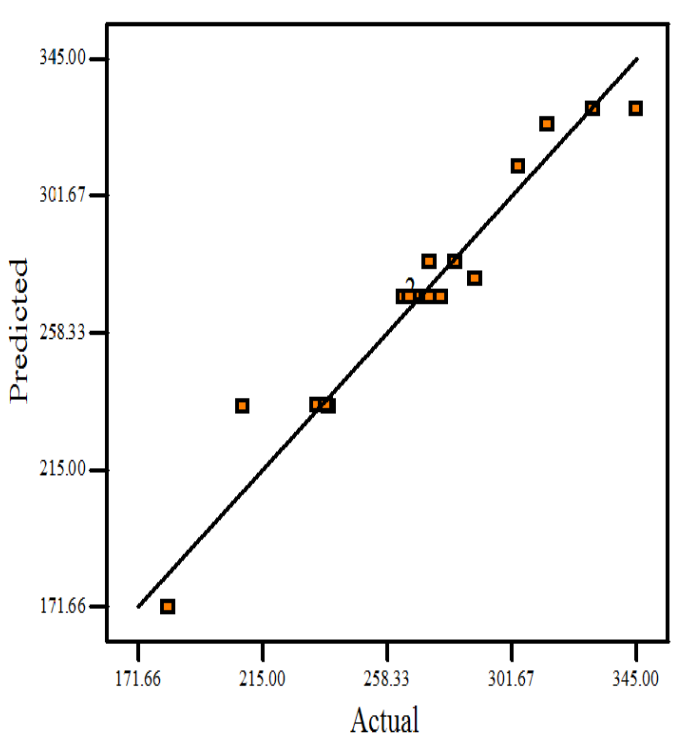

Figure 5: Predicted versus actual crystal size $\left(d_{p}, \mu m\right)$

Figure 6 shows the perturbation parameters effect of reaction temperature, $\mathrm{CO} 2$ mole fraction, and reaction time on sodium bicarbonate yield. Reference point are center values for the variables; $\mathrm{T}=50{ }^{\circ} \mathrm{C}, \mathrm{y}_{\mathrm{CO} 2}=60 \%$, $\mathrm{t}=1.5 \mathrm{~h}$. Reaction time and $\mathrm{CO} 2$ mole fraction were the most effective process variable of approximately equal effect.

Figure 7, shows the perturbation parameters effect on sodium bicarbonate crystal size. Reference point for the variables are $\mathrm{T}=70{ }^{\circ} \mathrm{C}$, and $\mathrm{t}=2.5 \mathrm{~h}$. Reaction temperature was the most effective process variable. Crystal size slightly increased with increasing reaction time, with negligible effect of $\mathrm{CO}_{2}$ gas content.

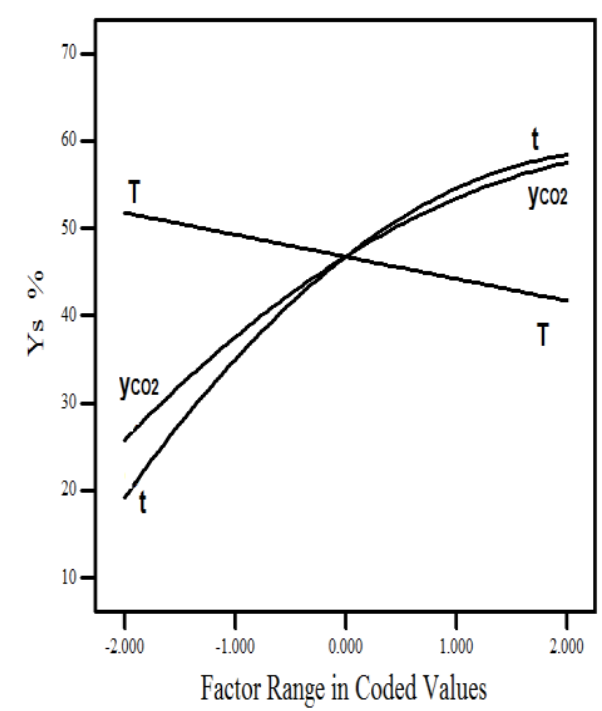

Figure 6: Effect of perturbation parameters on $\mathrm{NaHCO}_{3}$ yield 


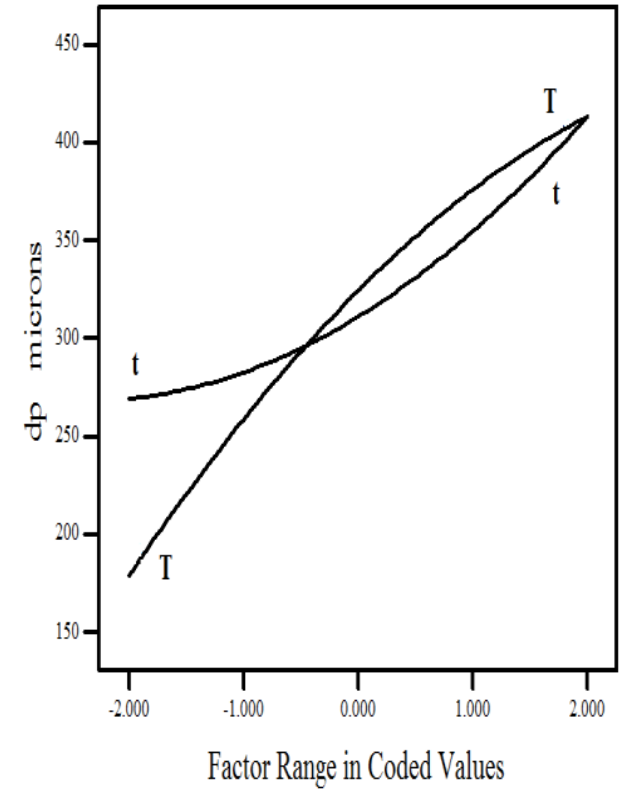

Figure 7: Effect of perturbation parameters on sodium bicarbonate crystal size

The optimum conditions achieved was $400 \mu \mathrm{m}$ particle size $\left(\mathrm{d}_{\mathrm{P}}\right)$ of sodium bicarbonate at reaction temperature $70{ }^{\circ} \mathrm{C}$, and time $2.5 \mathrm{~h}$, at any value of $\mathrm{CO}_{2}$ gas content (particle size was independent on $\mathrm{CO}_{2}$ gas content), as shown in Figure 8 . The range of bicarbonate yield from 32 to $63 \%$ was noticed for the optimum conditions of time and temperature at the range studied of $\mathrm{CO}_{2}$ gas content ( $\left.\mathrm{y}_{\mathrm{CO} 2}=20-100 \%\right)$.

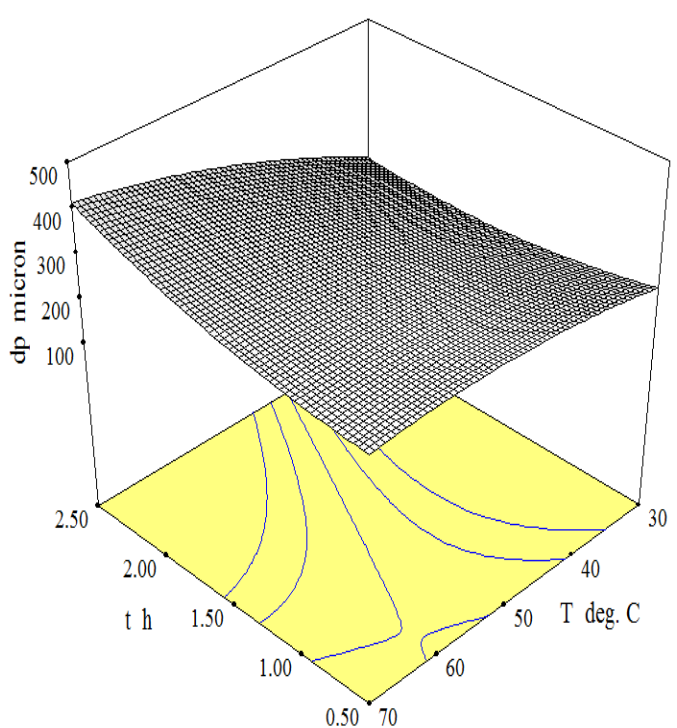

Figure 8: 3D plot for the interaction effect of temperature \& time on crystal size

For kinetic study purposes, a correlation of the experimental data of conversion $\left(\mathrm{Y}_{1}\right)$ at a time $\mathrm{t}_{1}$ before sodium bicarbonate precipitation were obtained, as follows;$$
\mathrm{Y}_{1}=16.99250+0.33125 \mathrm{~T}
$$$$
\left(\mathrm{R}^{2}=0.9997, \mathrm{Sd} .=0.051\right)
$$

$$
\begin{gathered}
\mathrm{t}_{1}=3.258+9.5 \times 10^{-3} \mathrm{~T}-0.057 \mathrm{yCO}_{\mathrm{CO}}+3.074 \times 10^{-} \\
{ }^{4} \mathrm{yCO}^{2}{ }^{2}
\end{gathered}
$$

Where; the total bicarbonate yield or conversion is; $\mathrm{Y}_{2}=\mathrm{Y}_{1}+\mathrm{Y}_{\mathrm{s}}$, and the total time is; $\mathrm{t}_{2}=\mathrm{t}_{1}+\mathrm{t}$

Figure 9 shows the effect of reaction time on conversion (equals to bicarbonate yield) at optimum operating reaction temperature $(\mathrm{T}=70$ ${ }^{\circ} \mathrm{C}$ ) at different values $\mathrm{CO}_{2}$ gas content.

For approximate process design approach, a zero order reaction with respect to both sodium carbonate and $\mathrm{CO}_{2}$ concentrations was assumed. The constant of the rate of reaction $\mathrm{k}_{\mathrm{o}}$ values obtained from the slopes (slope $=\mathrm{k}_{\mathrm{o}} / \mathrm{C}_{\mathrm{o}}$, $\mathrm{C}_{0}=1.887$ mole/l) of Figures 10 with corresponding correlation coefficients were 0.236 mole/l.h $\left(\mathrm{R}^{2}=8493\right), 0.472$ mole/l.h $\left(\mathrm{R}^{2}=0.9776\right)$, and 0.623 mole/l.h $\left(\mathrm{R}^{2}=9794\right)$ for $\mathrm{CO}_{2}$ gas content 20,60 , and $100 \%$ respectively.

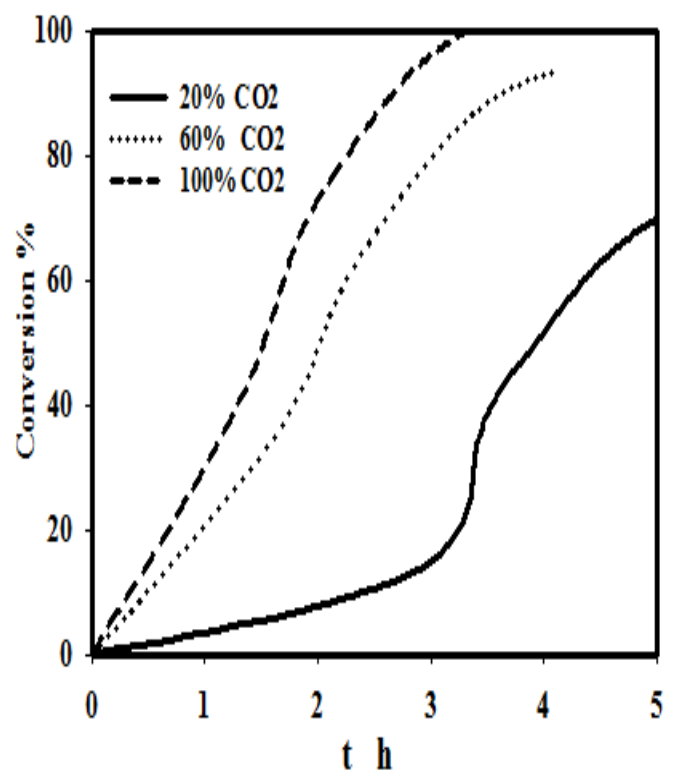

Figure 9: The effect of reaction time on conversion at optimum operating reaction temperature $\left(\mathrm{T}=70^{\circ} \mathrm{C}\right)$ and different values of $\mathrm{CO}_{2}$ mole fraction 


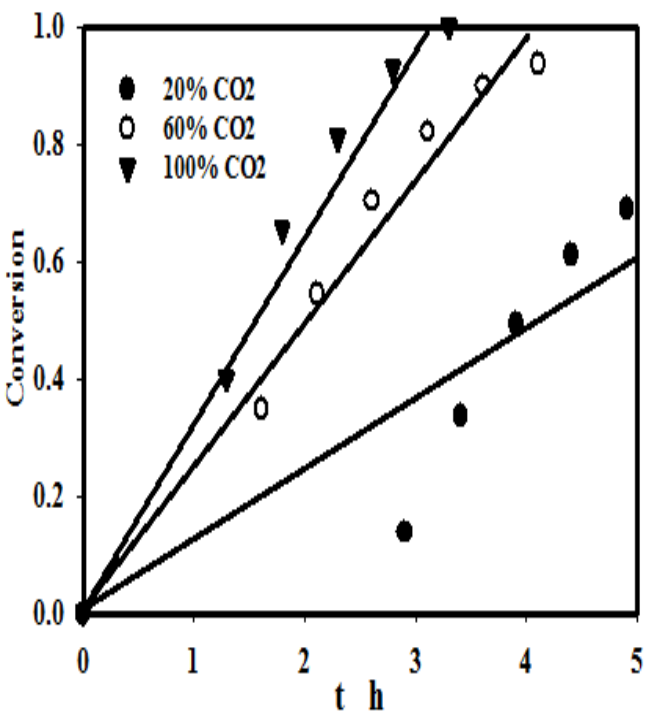

Figure 10: Zero order reaction with respect to both carbonate and $\mathrm{CO}_{2}$ concentrations

\section{Conclusions}

Batch bubble column was successfully applied to produce high particle size of sodium bicarbonate (about 400 micron), using response surface methodology (RSM). Second-order polynomial well fitted to the experimental data. Reaction temperature was the most effective variable on bicarbonate particle size. Higher particle size was obtained with higher temperature. Zero order reaction approximation with respect to both sodium carbonate and $\mathrm{CO}_{2}$ concentrations showed correlation coefficients higher than 0.97, except for low $\mathrm{CO}_{2}$ gas content (20\%) which was 0.8493 .

\section{Nomenclatures}

$\begin{array}{ll}\mathrm{C}_{\mathrm{o}} & \text { Initial concentration of carbonate, mole/l } \\ \mathrm{D} & \text { Diameter of bubble column, mm } \\ \mathrm{d}_{\mathrm{p}} & \text { Particle size (volume average), } \mu \mathrm{m} \\ \mathrm{d}_{\mathrm{pi}} & \text { Sieve size, } \mu \mathrm{m} \\ \mathrm{H} & \text { Height of bubble column, mm } \\ \mathrm{k}_{\mathrm{o}} & \text { Zero order reaction rate constant, mole/l.h } \\ \mathrm{L} & \text { Liquid level without gas flow, mm } \\ \mathrm{L}_{\mathrm{g}} & \text { Liquid level with gas flow, mm } \\ \mathrm{M}_{\text {Bicarb }} & \text { Sodium bicarbonate molecular weight, } \mathrm{g} / \mathrm{m} \\ \mathrm{m}_{\mathrm{Bicarb}} & \text { Solid sodium bicarbonate weight, } \mathrm{g} \\ \mathrm{M}_{\mathrm{Carb}} & \text { Sodium carbonate molecular weight, } \mathrm{g} / \mathrm{mol} \\ \mathrm{m}_{\text {Carb }} & \text { Sodium carbonate weight, } \mathrm{g} \\ \mathrm{n} & \text { Number of independent variables } \\ \mathrm{T} & \text { Temperature, }{ }^{\circ} \mathrm{C} \text { or } \mathrm{K} \\ \mathrm{t} & \text { Time of reaction, } \mathrm{h} \\ \mathrm{t}_{1} & \text { Time of reaction before precipitation, } \mathrm{h} \\ \mathrm{t}_{2} & \text { Total time of reaction, } \mathrm{h} \\ \mathrm{X}_{1} & \text { coded variable of reaction temperature, }{ }^{\circ} \mathrm{C} \\ \mathrm{X}_{2} & \text { coded variable of } \mathrm{CO}_{2} \text { gas content } \% \\ \mathrm{X}_{3} & \text { coded variable of reaction time } \\ \mathrm{X}^{*} & \text { Mole fraction of sodium bicarbonate } \\ & \text { saturation } \\ \mathrm{Y}_{1} & \text { Yield or conversion before precipitation } \\ & \end{array}$

$\mathrm{Y}_{\mathrm{S}} \quad$ Yield or conversion for precipitation time

$\mathrm{Y}_{2} \quad$ Yield or conversion for total reaction time

$\mathrm{y}_{\mathrm{CO} 2} \quad \mathrm{CO}_{2}$ gas content $\%$

$\mathrm{Z}_{\mathrm{i}} \quad$ Weight fraction of sieve no $\mathrm{i}$

\section{Greek symbols}

$\begin{array}{lc}\varepsilon_{\mathrm{g}} & \text { Gas hold-up } \\ \Delta \mathrm{L} & \text { Liquid level difference with and without gas } \\ & \text { flow, mm }\end{array}$

\section{Abbreviations}

ANOA Analysis of variances

CCD Central composite design of experiments

CSD Crystal size distribution

RSM Response surface methodology

Sd. Standard deviation

\section{References}

[1]. Shreve, R.N., Chemical Process, $2^{\text {nd }}$ Ed., McGraw-Hill, New York 1956.

[2]. Goharrizi A. , Abolpour B. , Modeling an industrial sodium bicarbonate bubble column reactor, Appl Petrochem Res, 4:235-245, (2014).

[3]. Goharrizi AS. , Abolpour B. , Estimation of sodium bicarbonate crystal size distributions in a steadystate bubble column reactor. Res Chem Intermed 38(7), (2012), 13891401.

[4]. Saberi A., Goharrizi AS., Ghader S., Precipitation kinetics of sodium bicarbonate in an industrial bubble column crystallizer. Cryst Res Technol 44(2), (2009), 159-166.

[5]. Wylock C., Larcy A., Cartage T., Haut B., Compartmental modelling of an industrial bubble column, 8th world congress of chem eng (WCCE8), Chemical Engineering Unit, Université Libre de Bruxelles), (2009).

[6]. Wylock C., Colinet P., Cartage T., Haut B., Coupling between mass transfer and chemical reactions during the absorption of $\mathrm{CO}_{2}$ in a $\mathrm{NaHCO}_{3}-$ $\mathrm{Na}_{2} \mathrm{CO}_{3}$ brine: experimental and theoretical study, International Journal of Chemical Reactor Engineering, 6:A4, (2008).

[7]. Wylock C., Larcy A., Colinet P., Cartage T., Haut B., Study of the $\mathrm{CO}_{2}$ transfer rate in a reacting flow for the refined sodium bicarbonate production process, Proceeding of COMSOL Conference Hannover, 2008.

[8]. Haut B., Halloin V., Cartage T., Cockx A., Production of sodium bicarbonate in industrial bubble columns. Chem Eng Sci, 59, (2004), 5687-5694.

at [9]. Prerylock C., Gutierrez V., Debaste F., Cartage T., Delplancke-Ogletree M.P., Haut B., Influence of mixing and 
solid concentration on sodium bicarbonate secondary nucleation rate in stirred tank: theoretical and experimental studies, Crys. Res. \& Tech., 45(9), (2010), 929.

[10]. Zhu Y., Haut B. , Halloin V. , Delplancke-Ogletree M. P. , Investigation of crystallization kinetics of sodium bicarbonate in a continuous stirred tank crystallizer, J. Crystal Growth, 282, (2005), 220-227.

[11]. Broul M., J. Nyvlt and O. Sohnel, Solubility in inorganic two component system, Elsevier, New York (1981).

[12]. Mullin J.W., Crystallization, 4th Edn., Butterworth-Heinemann, Oxford, 2001.

[13]. Stat-Ease, Inc., DesignExpert 6.0.6 user's Guide, Section 6 Response Surface Methods (RSM) Tutorials, 2000. 